\title{
A tradução do ritmo em Henri Meschonnic a partir da teoria de Émile Benveniste
}

\author{
Marina Bento Veshagem ${ }^{1}$ \\ Universidade Federal de Santa Catarina, Florianópolis, SC, Brasil
}

Resumo: Este trabalho apresenta o conceito de ritmo que embasa a teoria da tradução de Henri Meschonnic. $O$ autor defende o ritmo na linguagem, diferente daquele visto como alternância regular entre tempos fortes e fracos, desvinculado da música e de uma métrica prévias. A definição que contribui para tal formulação de ritmo nasceu na redefinição etimológica do conceito feita por Émile Benveniste. Ele mostra como o ritmo tem em sua etimologia a forma, enquanto movimento no instante em que é tomado e, assim, ele pode tornar-se múltiplo. Dessa maneira, o ritmo poderá ser definido como a organização do sentido no discurso, que produz uma semântica própria, a significância. Renovada pelo programa do ritmo, a tradução, por sua vez, será entendida como uma maneira de agir sobre a linguagem.

Palavras-chave: Ritmo; Tradução; Henri Meschonnic; Émile Benveniste.

Title: The translation of the rhythm in H. Meschonnic from the theory of Émile Benveniste

Abstract: This study presents the concept of rhythm that give base to the translation's theory by Henri Meschonnic. The author defends the rhythm in language, in a different way from what is seen as regular alternation between strong and weak beats, dissociated from previous music and metric. The definition that contributed for such formulation of rhythm is born in the etymological redefinition of the concept made by Émile Benveniste. He shows how the rhythm has in its etymology the form, as the movement in the instant where is taken and so he can became multiple. Thus, rhythm could be defined as the organization of meaning in discourse, which produces its own semantics, or significance. Renewed by the program of rhythm, translation, in turn, will be understood here as a way of acting on language.

Keywords: Rhythm; Translation; Henri Meschonnic; Émile Benveniste.

\section{Introdução}

Henri Meschonnic, em Poética do Traduzir (2010), propõe que o que se traduz é o ritmo. Criticando praticamente toda a teoria da tradução que foca em aspectos da tradução a partir de conceitos como fidelidade e equivalência e que vê o tradutor como sujeito que

\footnotetext{
${ }^{1}$ Mestre e doutora em Estudos da Tradução pela Universidade Federal de Santa Catarina (UFSC). Orcid: https://orcid.org/0000-0003-3790-6781. E-mail: maveshagem@gmail.com.
} 
levaria um texto de uma língua para a outra, procurando conciliar a primazia do sentido ou da forma, ele busca fundar a tradução como ação sobre a linguagem. O autor constata a exigência de uma teoria da tradução pensante pois, para ele, a história da tradução até hoje foi a da supremacia do signo em sua dualidade. Esta noção cria oposições, enquanto ideias contrárias, tais como significado versus significante, forma versus sentido, escrito versus oral. A maneira dual de pensar que ele quer recusar marca o descontínuo da linguagem, a inscrição de um sujeito como emissor de um enunciado, enunciado formado de palavras, palavras que compõem um sentido, sentido apresentado em uma forma. Essa configuração da linguagem, com a primazia do signo dual e tomando a palavra como unidade da língua, impede que a tradução aja sobre a linguagem.

A argumentação central de Meschonnic é de que a tradução pode se renovar e se tornar pensante através do programa teórico do ritmo como organização da historicidade do texto. O programa do ritmo faz trabalhar, juntos, conceitos como discurso, sentido e sujeito, que não são empregados em seus sentidos mais tradicionais, e sim forçados em seus limites. Trata-se de um programa teórico, porém entende-se que a teoria é sempre crítica e também que a teoria é a prática. Desse modo, o programa teórico do ritmo quer entendê-lo como diferente daquele subordinado à música, que o leva a ser pensado como alternância regular de tempos fortes e fracos ou duração e cadência de um movimento. Quando concebido a partir da associação entre poesia e música, o ritmo tem como atributos a generalidade, que Ihe imputa uma métrica prévia, e a universalidade, que quer fazer dele o mesmo em todos os tempos. O ritmo que o autor defende é diferente desse, é o da linguagem e tem em sua etimologia a forma, enquanto movimento no instante em que é tomado e, por isso, torna-se múltiplo. Essa é a grande contribuição de Émile Benveniste (BENVENISTE, 1976) que Meschonnic reconhece como essencial para o desenvolvimento de seu conceito de ritmo e que se tornou central em sua teoria da tradução. Assim, o ritmo será a organização do sentido em um discurso, criando uma produção única desses sentidos, a significância, pelas marcas dos significantes linguísticos e extralinguísticos.

O discurso aqui referenciado é compreendido como a atividade de linguagem de um sujeito numa sociedade e numa história. Entendido no Ocidente somente como uma passagem entre o pensar e o falar, ele passou a ser ultra valorizado e, ao mesmo tempo, extremamente temido, razão pela qual a sociedade encontra maneiras de controlá-lo e restringi-lo (FOUCAULT, 2008). O discurso que o programa do ritmo deseja é o da desordem, do descontrole, que tem algo de violento e que se pronuncia ao mesmo tempo em que inscreve um sujeito. Este sujeito é diferente do enunciador, é aquele que cria e é criado pela historicidade, e marca a subjetivação máxima de um discurso. Esses conceitos todos não atuam sozinhos, pois que falar de um é falar do outro, por isso eles trabalham juntos, sempre. Eles modificam a sociedade e são modificados por ela. 


\section{A problematização do conceito de ritmo}

Ritmo, seja no senso comum ou em âmbitos especializados, como da até mesmo da linguagem, costuma ser pensado a partir da música. Entretanto, o ritmo na linguagem como programa de organização da historicidade do texto não pode aportar o mesmo conceito da música. Não é que ele não possa existir ligado à música, mas não deveria haver uma teoria única de ritmo. Em Critique du rythme: anthropologie historique du langage ${ }^{2}$ (1982), Meschonnic desenvolve uma teoria - lembrando que, portanto, crítica - do ritmo enquanto conceito que agrega obrigatoriamente as noções de sentido (significância) e sujeito. "Porque o que toca a poesia toca a teoria geral da linguagem, e por isso o sujeito, o político, a história, uma busca sobre o ritmo no discurso é condução a uma antropologia histórica da linguagem"3 (MESCHONNIC, 1982, p. 44).

Meschonnic empreendeu uma exaustiva consulta ao conceito de ritmo nos dicionários, notando que todos fundam o ritmo sobre a noção de regularidade que caracteriza a etimologia antiga (criticada por Émile Benveniste). Os dicionários consultados são principalmente franceses, mas não somente, e foram divididos em cinco tipos: 1) dicionários históricos de grande dimensão, do século passado, mas ainda de referência usual: Littré, Larousse do século XIX, Darmesteter et Thomas, dicionário russo de Dal' e o Oxford English Dictionary; 2) pequenos dicionários cotidianos, com linguagem de uso atual: le Petit Larousse, le Petit Robert, le Dictionnaire du Français Contemporain (Larousse), o Concise Oxford Dictionary, o Diccionario Porrúa de la lengua española; 3) dicionários da língua moderna, de grande formato: o Dicctionnaire de la langue française de Paul Robert e o Grand Larousse de la langue française; 4) as enciclopédias modernas de grande formato: a Encyclopaedia Universalis, a Encyclopaedia Britannica, a Brockhaus Enzyklopäedie e a Grande Encyclopédie Larousse; 5) dicionários especializados, de nível técnico. Em linguística, o Dictiononaires de linguistique (Larousse) e o Dictionnaire encyclopédique des sciences du langage de Ducrot-Todorov; em poética, a Encyclopaedia of Poetry E Poetics de Princeton, a Kratkaïa Literaturnaja Enciclopedija de Moscou e o Dictionnaire de la musique de Marc Honegger; e na filosofia, o Vocabulaire de Lalande, o Dictionnaire de la langue philosophique dos P.U.F. e a Enciclopedia filosofica italiana (MESCHONNIC, 1982).

As conclusões a que chegou Meschonnic é que todos os dicionários dizem a mesma coisa, apesar de algumas nuances e situações particulares. O autor explica que eles misturam ordens distintas, como o cósmico-biológico e a ordem histórica, que é a da linguagem, por isso acredita que eles se equivocam. Assim, com tais definições e embasamentos, os dicionários apresentam-se como verdade universal, como teoria única do ritmo. Em alguns casos eles partem do particular antropológico (música - poesia) para

\footnotetext{
${ }^{2}$ Este livro ainda não possui tradução publicada em português, por este motivo, todas as citações dele que forem feitas neste trabalho serão traduções minhas.
} 
estender ou metaforizar o cósmico, o biológico; outros partem do geral para ir ao particular. Aí estaria também um problema para Meschonnic: concebido assim, o ritmo seria um antesda-linguagem ("avant-le-langage"), mas antes da linguagem ainda é a linguagem.

As definições atribuídas ao ritmo no Brasil não são muito diferentes daquelas analisadas por Meschonnic. Tomemos como exemplo a conceituação que faz o Novo Dicionário Aurélio da língua portuguesa (2009):

ritmo . [Do gr. rhytmós, 'movimento regrado e medido', pelo lat. rhytmu.] E. M. 1. Movimento ou ruído que se repete, no tempo, a intervalos regulares, com acentos fortes e fracos: o ritmo das ondas, da respiração, da oscilação de um pêndulo, do galope de um cavalo, 2. No curso de qualquer processo, variação que ocorre periodicamente de forma regular: o ritmo das marés, das fases da Lua, do ciclo menstrual. 3. Sucessão de movimentos ou situações que, embora não se processem com regularidade absoluta, constituem um conjunto fluente e homogêneo no tempo: o ritmo de um trabalho. 4. Nas artes, na literatura, no cinema, etc., a disposição ou o desenvolvimento harmonioso, no espaço e/ou no tempo de elementos expressivos e estéticos, com alternância de valores de diferente intensidade: o ritmo de uma escultura, de uma peça de teatro. 5. Arte Poét. Num verso ou num poema, a distribuição de sons de modo que estes se repitam a intervalos regulares, ou a espaços sensíveis quanto à duração e à acentuação. 6. Mús. Agrupamento de valores de tempo combinados de maneira que marquem com regularidade uma sucessão de sons fortes e fracos, de maior ou menor duração, conferindo a cada trecho características especiais. 7. Mús. A marcação de tempo própria de cada forma musical: ritmo de marcha, de valsa, de samba. 8. Mús. O conjunto de instrumentos de percussão e outros similares que marcam o ritmo (6) na música popular; bateria. 9. Bras. O conjunto de ritmistas [v. ritmista (1 e 2)]. Ritmo circadiano. Biol. 1. Ritmo espontâneo, próprio de cada espécie animal ou vegetal, a partir de certa fase evolutiva, observado em condições ambientais constantes, mas não influenciável por iluminação, e que se manifesta de acordo com o momento do dia, por variações periódicas das funções biológicas (respiração, circulação, digestão, secreções endócrinas, etc); pode ser observado até mesmo em nível celular. Ritmo de galope. Card. 1. Desdobramentos da primeira bulha cardíaca, de modo que, pela ausculta, se ouvem três ruídos cardíacos, separados por pausas; ruído de galope. Em ritmo de Brasília.

Todos os sentidos apresentados caracterizam o ritmo em sua noção de regularidade; talvez à exceção do 4, que fala de desenvolvimento harmonioso (não exatamente regular), mas indica que depende da alternância de valores de diferente intensidade. De 1 a 3, as definições partem de um conceito geral para chegar ao particular - biologia, natureza, etc. Já de 5 a 9 tratam do ritmo na música, mesmo quando aparecem no verso ou no poema. Os últimos são claramente os da biologia, sentido genérico, porém sempre da regularidade.

A crítica geral que emprestamos de Meschonnic aos dicionários é a de que eles apenas representam o consenso, fornecem a verdade da opinião, a média dos conhecimentos. "Mas não é a prova da verdade o que eles dizem. Esta unanimidade define ao mesmo tempo um saber comum, e uma origem comum. As cartas geográficas antigas também se pareciam" (MESCHONNIC, 1982, p. 151).

Outros estudos no Brasil, para além dos dicionários também chegam a conclusões parecidas. Para Mário de Andrade (1995), por exemplo, o ritmo é, a princípio, a “organização 
intelectual do movimento por meio de subdivisões de tempos e acentos" (ANDRADE, 1995, p. 71). Por pensar no ritmo em sua relação com a música neste livro, ele considera que a música se realiza no tempo, por isso o ritmo é seu elemento primordial de manifestação. 0 tempo, por sua vez, é para o autor como uma entidade abstrata pela qual se compreende de maneira consciente a duração, que seria o princípio de todo movimento e de toda vida. $A$ organização do tempo a partir da natureza fisiológica do homem, e a mais importante série de golpes fisiológicos pelos quais sentimos a vida, é a circulação do sangue em toda a concatenação de seus fenômenos: respiração, pulsação, etc. Assim, a partir da fisiologia, Mário de Andrade entende o ritmo como organização da nossa natureza interior, não mais exterior, e por meio dele se organizariam o tempo e a expressão artística. Temos, então, que o ritmo para o autor é toda e qualquer organização expressiva do movimento, mas que ainda parte de seu sentido abstrato, para se resolver no fisiológico, e ligado à música.

Dessa maneira, segundo as diversas conceituações tradicionais de ritmo, este deveria ser a realização particular de um princípio simples de alternância, uma variação fundamental do mesmo e do diferente: ritmos cósmicos, biológicos; ritmos humanos do trabalho, da música, da linguagem. Mas o paradoxo para o qual aponta Meschonnic é que quanto mais se atribui importância a essa noção, mais ela se torna vaga. "Autorizando o inefável, o rigor, no geral, era parente próximo do álibi no caso particular: tal ritmo lembrava Um Tal. Não se trata da pluralidade de ritmos, mas da pluralidade do ritmo" (MESCHONNIC, 1982, p. 145146). Dessa concepção resulta que tudo é ritmo e, assim, de maneira genérica, abstrata, ele passa a ser encontrado em todo lugar. São identificadas pequenas sombras dessa grande unidade de ritmo em toda parte, mas onde estariam seus fragmentos diferentes, plurais?

A teoria de ritmo que tem base na concepção de Meschonnic não é apenas uma crítica das diversas teorias de ritmo existentes. Ela funda o ritmo na linguagem como discurso, e não como categoria abstrata e universal. E, assim, se tomado o ritmo na e pela linguagem, e a linguagem no e pelo ritmo, há busca de uma organização do sentido de sujeitos históricos, o que permite ao sentido tornar-se infinito, fragmentar a unidade, a totalidade. No entanto, mesmo em Meschonnic, a teoria do ritmo não está dada, pronta. Nem a teoria do ritmo, nem a teoria do sentido e nem a do sujeito estão constituídas. Podemos aprender com ele que nenhuma teoria nunca estará constituída. "O erro inicial seria esperar, para uma, que a outra esteja mais assegurada. Nenhuma das três é prérequisito para a outra. Salvo que se espere indefinidamente. Se o sentido, o sujeito, o ritmo estão ligados, trabalhar um é trabalhá-los juntos" (MESCHONNIC, 1982, p. 78).

Tais teorias iniciam seu confronto na crítica e nas consequências da relação entre poesia e música na definição de ritmo. Para Meschonnic, o ritmo na poesia é radicalmente diferente do ritmo na música, e também seriam ilusórias uma definição e uma história comuns a eles. "É diferente porque é linguagem, da mesma forma que é na linguagem" (MESCHONNIC, 1982, p. 121). As unidades do ritmo para uma e outra são incompatíveis e os termos técnicos também são diferentes. 
Associar música e poesia nos faria assumir os dois atributos inseparáveis, questionáveis e indesejáveis do ritmo: a generalidade e a universalidade. A generalidade inclui a métrica no ritmo, ou o ritmo na métrica, o que exige um enorme nível de abstração para neutralizar suas diferenças. A universalidade é a invariabilidade temporal da definição de ritmo: o ritmo é sempre o mesmo em todos os tempos. A partir destes atributos, a definição etimológica do ritmo surgiria, então, da música, como ritmo-regularidade ("rythme-régularité", MESCHONNIC, 1982). Citando o Traité de rythmique et de métrique grecques, de Othon Riemann e Médéric Dufour (apud MESCHONNIC, 1982), Meschonnic mostra a formulação deste conceito de ritmo-regularidade, que parte da afirmação de que o ritmo, musical ou poético, é constituído pelo retorno, em intervalos iguais, de um som (nota de música ou sílaba), mais forte que outros.

Em sua origem antiga, a noção de ritmo unia a poesia e a música. Para os gregos antigos, a música incluía a harmonia do cosmos, unindo a astronomia e a língua grega. De Pitágoras a Santo Agostinho, o número era a manifestação dessa harmonia. Na poesia grega primitiva os versos eram cantados, o que demonstra essa união entre poesia e música. Mais tarde, desde o início do período alexandrino, os versos passaram a ser recitados. Os estudos sobre essa mudança, como em Riemann-Dufour, citado anteriormente, referem que esta mudança veio acompanhada de um sentimento de perda, com certa nostalgia, a qual Meschonnic contesta, argumentando que, se um ritmo é linguístico, e se há continuidade linguística, não deveria haver perda. “Esta 'união íntima' não diz nada de seu funcionamento respectivo. Suas razões são rituais, históricas. Esquecendo o que ela tinha significado, tomou-se essa união por um parentesco genético." (MESCHONNIC, 1982, p. 123). A ideia de perda e de nostalgia regeu as teorias da linguagem no século XVIII, que reforçaram a união de poesia e música.

Origem e visada do ritmo, comunhão antes ou depois da linguagem, a música, de vínculo primeiro, antropológico, passou ao metafórico, depois cliché: a "lira", "Poeta, toma seu luth...", "cantar", chanter la gloire diz o Petit Larousse. Paradoxalmente, a música se tornou para a poesia um álibi do ritmo. $O$ estado da poesia pura levou-a a seu último grau, pois aí ela figura o inefável. Fiança do vago, é o ritmo-emoção. Uma licença de místico, em que a noção de ritmo se fundiu na essência da vida (MESCHONNIC, 1982, p. 124).

De ritmo-regularidade, a definição passa assim para a de ritmo-emoção, na qual, a música de um texto é apenas uma metáfora. Para Meschonnic, esse estado de união entre música e poesia é um obstáculo epistemológico à análise e à teoria do ritmo na linguagem, pois não se têm nem os conceitos e nem os meios para fazê-lo. "O ritmo é então um universal poético. Mas quando sua noção se torna extensiva à poesia mesmo, sua compreensão se dilui na compreensão da poesia. Ambas, em termos de experiência, são então um só e mesmo inefável" (MESCHONNIC, 1982, p. 125). O ritmo, quando restrito à prosódia (que Meschonnic entende como organização consonântico-vocálica), é separado do sentido. A música se torna assim uma categoria utilizada para se desfazer do modo poético de significar. 
O argumento é que não há uma troca equilibrada nessa relação: a história comum da música e da poesia produziu um efeito de discurso que se sustenta nessa suposta circularidade - poesia é música, música é poesia - e assim, uma expressão como "linguagem musical" traz muito mais termos tomados da música para designar fatos de linguagem ou de literatura do que o contrário. Nesse discurso, as relações da linguagem com a música se dão por meio de analogias, por comparação entre as relações hierárquicas de sons entre eles e a organização de palavras nas sintaxes. (MESCHONNIC, 1982).

Para Meschonnic, na teoria da linguagem e da poesia, há de se reconhecer que toda comparação da poesia com a música, do ritmo na poesia com o ritmo na música, é contralinguagem e contra-poesia.

\footnotetext{
Pois o ritmo, na linguagem, só existe no discurso. Quando se trata do ritmo na linguagem, trata-se apenas do discurso. Da mesma forma que não há em música nem dupla articulação (consoantes-vogais, e palavras), nem linearidade obrigatória, não há discurso. Também, inversamente, não há sons na linguagem, mas somente fonemas, quer dizer somente sentido, com todos os gestos, os ruídos e os gritos do corpo que o cercam e o penetram sem ser linguagem - mas que não são sons, mas os significantes do corpo, em todos seus estados (MESCHONNIC, 1982, p. 128).
}

Um dos problemas decorrentes da associação dos conceitos de poesia e música é propiciar uma identificação do ritmo com a medida, com a métrica, que seguiu nutrindo a teoria do verso. No século $X X$, então, fortaleceu-se a noção de metrificação do ritmo, relacionado à música, com a propagação e a generalização da coincidência do ritmo e da medida. Tal coincidência cria uma contradição se aplicada à teoria do verso: a métrica na música e na poesia não coincide necessariamente. Na música o tempo forte está, a princípio, no primeiro verso, enquanto na poesia - particularmente aquela em francês - costuma estar na última sílaba do grupo rítmico. Além disso, para a teoria do verso e da linguagem, o ritmo é indivisível, ao contrário da métrica, que pode ser dividida. A métrica é sempre a pequena unidade, e o ritmo é uma organização de grandes e pequenas unidades, a relação entre elas (MESCHONNIC, 1982).

Além disso, um mesmo ritmo não corresponde necessariamente a uma mesma métrica, segundo o estudo de Marina Tarlinskaïa (English Verse, Theory and History, Mouton, 1976 - Moscou, 1973 - apud MESCHONNIC, 1982). Meschonnic cita este estudo por considerar um exemplo importante, e mais recente, de uma longa tradição e se aplicar a uma métrica de uma língua que não a russa. A autora mostra como o início (os dois primeiros pés) de um verso de Shakespeare, fica no quadro iâmbico em inglês, mas em uma tradução russa do drama ele não é nada iâmbico. As tradições não são as mesmas, além disso, um mesmo verso, já que é ritmado linguisticamente, pode ser metrificado ou não segundo as épocas. Ele pode até ser diferente se estiver em um drama de Shakespeare ou em seus Sonetos.

Outro exemplo de como uma coincidência de métrica não corresponde necessariamente a uma coincidência rítmica é também citado por Meschonnic. Os dois 
versos alexandrinos seguintes - o primeiro de Phèdre, de Racine, e o segundo de Epîtres, de Nicolas Boileau-Déspreaux - têm um corte rítmico idêntico: "Vous mourûtes au bord où vous fûtes laissée. Le chagrin monte en croupe et galope avec lui." ${ }^{4}$ (apud MESCHONNIC, 1982, p. 206).

No entanto, Meschonnic apnta que aí não há semelhança de ritmo. O segundo verso fala do galope, mas o sentido vem antes da expressividade, então, ritmicamente esses versos não são comparáveis. Além disso, nenhum limite de palavra, e sobretudo de grupo rítmico, é o mesmo; a estrutura do grupo "monte en croupe" com um monossílabo que traz à mente o sentido completo (monte), e a relação sintagmática ambígua do grupo nominal com o grupo verbal (le chagrin monte...), instalam um acento rítmico, e não métrico, sobre monte; de onde um contra-acento, sequência de dois acentos, que o verso precedente não tem. O ritmo dos timbres também é diferente de um para outro, essencialmente vocálico, assonante, em série ternária (vous mourûtes, où vous fûtes) no primeiro; consonântico aos pares (chagrin, croupe; croupe, galope) no segundo, e não nas mesmas posições. Somente a escansão métrica é a mesma: cesura no 6‥

\begin{abstract}
Havia apenas similitude metricamente. Contradição interna da retórica, que só pode ser retórica do sentido, do discurso - e que não pode tomar o verso, o ritmo, como sentido e discurso. É que a retórica colocou a ordem antes do sentido, a taxinomia antes do discurso. Além disso, no discurso, ela mantém apenas a língua. E este exemplo também mostra que o ritmo é a organização do discurso (MESCHONNIC, 1982, p. 207).
\end{abstract}

Por isso, o desafio, quando se traduz, é de não cair na retórica pura, isolada da poética e do ritmo na linguagem. $O$ cuidado na tradução é de não colocar a retórica antes do sentido; ao fazer uma escolha de tradução, é preciso ler e ouvir como o ritmo organiza o discurso e os sentidos antes de fazer uma escolha apenas retórica. Esta, assim como a métrica, entra no ritmo, mas não existe como prévia a ele.

O plano em que acontecia a confusão entre a música e a linguagem e que, historicamente, justificava uma definição comum do ritmo, era o canto. Isso porque a métrica é originalmente própria do cantado. Assim que começou a se abandonar o canto - o metrificado - e desde o recitativo, a ordem da linguagem retomou a prioridade sobre a da música. "Daí o estranho problema da métrica: fazer corresponder os versos, que são do discurso, a uma métrica ideal, um desenho abstrato - o vício do círculo onde não se pode saber se deduz-se o discurso do esquema ou se induz-se o esquema do discurso" (MESCHONNIC, 1982, p. 134). E o ritmo acabou preso no esquema de correspondência:

\footnotetext{
${ }^{4}$ Das inúmeras possíveis traduções desses versos, trago aqui uma possibilidade de tradução livre que não se preocupa em seguir o corte rítmico, que ambos compartilham, nem mesmo o ritmo, já que para isso seria necessário traduzir o texto em seu discurso. Esta tradução tem como objetivo apenas ser referência de sentido para compreensão da análise proposta por Meschonnic: "Foste moribunda bem onde foste abandonada. A mágoa monta em garupa e galopa com ele"
} 
havia de fazê-lo caber ele na métrica prévia. Sobretudo na tradução, em que a medida aparece como desafio ao bom tradutor, mas se revela como clausura e que leva à ignorância do ritmo.

Como consequência dessa concepção de ritmo ao longo da história, três elementos acontecem inseparavelmente quando ele é pensado hoje: a primazia da noção de regularidade para defini-lo, a confusão entre o ritmo e a métrica, e a primazia da métrica sobre o ritmo. A reciprocidade entre os três permanece enquanto um deles existir. Para mudar isso, Meschonnic propõe integrar a métrica ao discurso, contra a tradição e num movimento contrário ao dela. Esse é o mesmo movimento que combate a tradição da teoria do ritmo com certa soberania da música. "Resta, no lugar de pressupor uma teoria única do ritmo comum à linguagem e à música, estudar se há uma especificidade do ritmo na linguagem, e qual, com relação a uma especificidade do ritmo na música. A teoria única jamais levará a isso: ela proíbe" (MESCHONNIC, 1982, p. 136).

Quando a métrica é integrada ao discurso, deixa-se de identificar a teoria do ritmo e a do metro como opostas - o que seria proposta da teoria tradicional. À unidade binária do dualismo, o discurso opõe a pluralidade interna do ritmo, teoria do sentido. O ritmo é sem medida porque segue uma outra racionalidade, não porque ele se opõe à métrica. Ele não se opõe ao rigor, o rigor é outro, o do sentido, que não se mede. Um exemplo disso, para ficar no teatro, é a análise que faz Meschonnic da significância da difusão do nome de Ofélia na linguagem em Hamlet. Ele notou que em todas as vinte vezes em que o nome de Ofélia é citado nos diálogos da peça em inglês, há elementos consonânticos ou vocálicos do nome no entorno imediato. “(...) estas palavras colocadas nas extremidades, do começo ao fim da peça, não constituem uma lista aleatória, mas um acompanhamento cheio de sentido: o sentido deste nome nesta peça. Estas palavras apelam para o que caracteriza Ofélia e para aquilo que constrói o seu destino" (MESCHONNIC, 1982, p. 111). Aí não se trata apenas de unidades de sentido, pois um nome próprio seria uma designação, mas das palavras ativas formando significações. A designação da personagem conduz o sentido na peça, uma semântica da prosódia, uma encenação, dentro da peça, do próprio nome de Ofélia. Significantes da beleza e da doçura, depois da loucura e da morte aparecem nessa relação sobretudo consonântica com "Ophelia". Trago aqui apenas um dos exemplos de como isso acontece, que é a série mais longa do significantes de Ofélia em proximidade, quando Hamlet percebe que é ela quem se enterra: "What, the fair Ophelia!" (v, 1, 231 MESCHONNIC, 1982, p. 119). E a rainha diz: "[Scattering flowers] Sweets to the sweet. Farewell. / I hoped thou shouldst have been my Hamlet's wife. / I thought thy bride-bed to have decked, sweet maid, / And not t'have strewed thy grave" (v. 232-235 - MESCHONNIC, 1982, p. 119-120). Meschonnic nota que "sweet", redobrado, é colocado entre "fair" e "farewell", a primeira palavra é o retrato e a segunda o destino de Ofélia. Ela é o personagem a quem, pela prosódia, mais se dá adeus na peça.

Um dos problemas da universalização é que ela não permite a história do ritmo. Assim, passa a existir imediatamente uma métrica universal, autônoma, que é preexistente 
ao poema: há um ritmo iâmbico antes de haver um poema iâmbico. Meschonnic propõe que, diante dessa noção tradicional de ritmo tão atrativa, faça-se uma escolha: ou se continua a privilegiar a definição geral que desconhece o discurso incluído na métrica, ou se parte empiricamente do discurso, que leva a uma teoria do ritmo particular aos modos de significar.

\section{A redefinição de Benveniste para ritmo}

Até então discutimos mais sobre como não entender o ritmo, associado à música, enquanto regularidade e a partir da métrica, proponho agora falarmos sobre o que ele é. As indicações para compreensão do programa do ritmo começam com a teoria Émile Benveniste, muito cara a Meschonnic e que ajuda a repensar etimologicamente o conceito e ver sua multiplicidade. Segundo Meschonnic, a crítica de Benveniste, da etimologia que ele busca, quase constitui a definição atual de ritmo e não só desestabilizou sua noção como também sua inserção na teoria do signo e, assim, a própria teoria do signo. A noção de ritmo não se coloca mais unicamente em uma forma, não é mais auxiliar do dualismo. Como "disposição", "forma do movimento", "disposição", "configuração"; ela deixa a definição fixa que a mantinha no signo e permite que entre no discurso. "E como o discurso não é separável de seu sentido, o ritmo é inseparável do sentido deste discurso. O ritmo é organização do sentido no discurso" (MESCHONNIC, 1982, p. 70). E se ele é organização, não é mais em um nível distinto, justaposto.

Benveniste, em Problemas de Linguística Geral I (1976), dedica um capítulo à noção de ritmo na sua expressão linguística. Ele traça um caminho para demonstrar como o conceito associado, em sua origem, ao movimento das ondas na praia foi, em realidade, metaforizado por nós contemporaneamente. A palavra "ritmo", do grego, nos veio através do latim. A palavra " $\rho \cup \theta \mu o ́ \zeta$ " em grego designa o ritmo, o que deriva do fato de ser o abstrato de "fluir". Essa noção teria vindo da observação do movimento das ondas. Benveniste explica que, no entanto, essa ideia de o movimento regular das ondas ter feito nascer no espírito do homem a ideia de ritmo não se revela possível semanticamente: o mar não flui. Quer dizer, fluir jamais se diz do mar e nunca se emprega para o movimento das ondas. O que de fato flui é o rio, o riacho. Assim, o sentido da palavra grega "fluir" não tem relação com o ritmo; uma corrente não tem ritmo.

O autor faz então uma recuperação histórica dos usos da palavra "fluir" em grego, para fundamentar sua significação a partir de seu emprego desde a alta antiguidade. Ela está ausente dos poemas homéricos, mas é encontrada nos escritores jônios e na poesia lírica e trágica, depois na prosa ática, principalmente nos filósofos. Dessa maneira, ele chega a que "fluir" significa "forma" (бхń $\mu \alpha$ ) desde os criadores do atomismo Leucipo e Demócrito, entendendo sempre como forma distintiva, o arranjo característico das partes num todo.

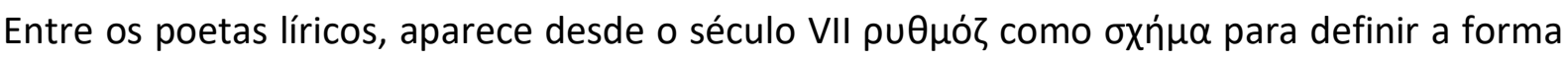


individual e distintiva do caráter humano. Entre os trágicos ela também aparece com o sentido de forma, o que permanece até a prosa ática do século $\mathrm{V}$.

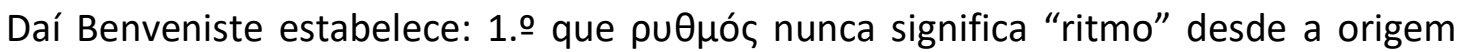
até o período ático; 2. que nunca se aplica ao movimento regular das ondas; 3. que o sentido constante é "forma distintiva, figura proporcionada, disposição" (BENVENISTE, 1976, p. 366), nas mais variadas condições de emprego. Ainda concluiu que os derivados compostos, nominais ou verbais, da palavra grega, sempre se referem apenas à noção de forma.

Não descartando a negação inicial da relação entre ritmo e fluir ( $\rho \varepsilon ́ \omega)$ - pois sua crítica não foi direcionada à derivação, mas ao sentido inexato deduzido da palavra -, Benveniste retorna à etimologia. A formação com sufixo $-(\theta) \mu o ́ \varsigma$ confere às palavras "abstratas" não o cumprimento da noção, mas a modalidade particular do seu cumprimento: não o fato de dançar, mas a dança particular vista no seu desenvolvimento; não o fato de se manter, mas a maneira de manter-se, o equilíbrio de uma balança, ou pausa ocasional. Entretanto, ele acredita que é ao radical que devemos nos ater. A relação entre

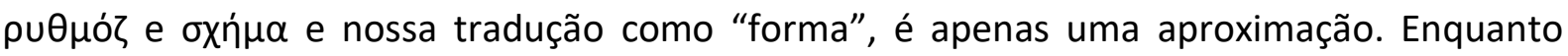
$\sigma \chi n ́ \mu \alpha$ fala da forma fixa, pronta, $\rho \cup \theta \mu o ́ \zeta$, pelos contextos em que aparece, designa a forma no instante em que é assumida por aquilo que é movediço, móvel, fluido, improvisado, momentâneo, modificável. "Pode-se compreender então que $\rho u \theta \mu o ́ \zeta, ~ s i g n i f i c a n d o$ literalmente 'maneira particular de fluir', tenha sido o termo mais próprio para descrever 'disposições' ou 'configurações' sem fixidez nem necessidade natural, resultantes de um arranjo sempre sujeito à mudança." (BENVENISTE, 1976, p. 368)

Se ritmo tem etimologicamente a ver com a maneira de fluir, um movimento tomado em certo instante, não fixo e momentâneo, o conceito toma seu caráter de multiplicidade. "O sentido pode fazer que o mesmo não seja mais o mesmo" (MESCHONNIC, 1982, p. 147). A cada instante, mesmo que a métrica encontre figuras idênticas de número, ordem, posição de elementos no discurso, os sentidos podem ser diferentes. "'Give me your hand', não tem a mesma significação, então não tem a mesma entonação, o mesmo ritmo, em Júlio César (IV, III, 119) e em O Mercador de Veneza (IV I, 264)" (MESCHONNIC, 1982, p. 147). A multiplicidade de ritmos se torna a multiplicidade interna do ritmo, o que implica em multiplicidade de sentidos.

O ritmo é o conjunto sintético de todos os elementos que com ele contribuem, organização de todas as unidades pequenas e grandes, desde aquelas da frase até as da estória, com todas suas figuras. (...) Eu defino o ritmo na linguagem como a organização das marcas pelas quais os significantes, linguísticos e extralinguísticos (no caso da comunicação oral sobretudo) produzem uma semântica específica, distinta do sentido lexical, e que eu chamo de significância: quer dizer os valores, próprios a um discurso e a um só. Essas marcas podem se situar em todos os "níveis" da linguagem: acentuais, prosódicos, lexicais, sintagmáticos. (MESCHONNIC, 1982, p. 216). 
A significância é de todo o discurso e está para além do sentido tradicional lexical, pois os significantes são tanto sintáticos quanto prosódicos. O ritmo, assim, engloba a prosódia, e no falado, a entonação. "Organizando junto a significância e a significação do discurso, o ritmo é a própria organização do sentido no discurso. E o sentido sendo a atividade do sujeito da enunciação, o ritmo é a organização do sujeito como discurso dentro e por seu discurso" (MESCHONNIC, 1982, p. 217). Meschonnic indica que podemos reconhecer três categorias de ritmo, mescladas no discurso: o ritmo linguístico, aquele do falado em cada língua, ritmo de palavra ou de grupo, e de frase; o ritmo retórico, variável segundo as tradições culturais, as épocas estilísticas, os registros; e o ritmo poético, que é a organização de uma escritura. E cada escritura inventa seus ritmos e inventa novos ritmos sem parar.

\section{Conclusão}

Se tantas traduções foram e ainda seguirão sendo feitas dessa forma, a partir da noção de linguagem que a reduz às unidades da língua, poderíamos nos perguntar: por que aprender ou reaprender a escutar? Como a concepção de linguagem do tradutor sempre acaba exposta em sua tradução, aquele que não ouve o ritmo sempre proporá uma tradução que tenta dizer o que diz o texto original, mas que não produz sons, que não ouve seu ritmo. Traduzir, vislumbrado como um modo de ação sobre a linguagem, é ato de transformação dos modos de sentir, ver, agir, falar. É política. E a tradução só adquire essa capacidade, como atividade - que supõe que a linguagem faz alguma coisa ao mesmo tempo em que diz algo. Aí está a contribuição de Meschonnic para a tradução a partir do conceito de ritmo de Benveniste. A tradução, quando poética, é contemporânea do que movimenta a linguagem e a sociedade.

\section{Referências}

ANDRADE, M. de. Introdução à estética musical. São Paulo: Hucitec, 1995.

BENVENISTE, É. Problemas de linguística geral. São Paulo: Ed. Nacional, 1976.

FERREIRA, A. B. de H. Novo dicionário Aurélio da língua portuguesa. 3. ed. rev. e atual. São Paulo: Fundação Dorina Nowill para Cegos, 2009.

FOUCAULT, M. A ordem do discurso. Trad. Laura Fraga de Almeida Sampaio. 16. ed. São Paulo: Edições Loyola, 2008.

MESCHONNIC, H. Poética do traduzir. Trad. Jerusa Pires Ferreira e Suely Fenerich. São Paulo, Perspectiva: 2010.

MESCHONNIC, H. Critique du rythme: Anthropologie historique du langage. Paris: Verdier, 1982. 
MESCHONNIC, H. Linguagem, ritmo e vida. Trad. Cristiano Florentino Belo Horizonte: Fale/UFMG, 2006.

Recebido em: 10/12/2019.

Aceito em: 07/03/2020. 